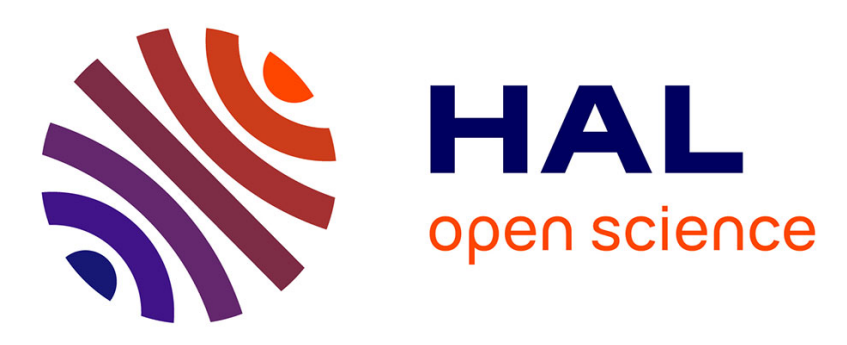

\title{
Integration of the volume segmentation method into an optimization process: application to the sizing of a micro-actuator for deformable mirrors
}

Harijaona Lalao Rakotoarison, Frédéric Wurtz, Jiri Stepanek, Benoît Delinchant, Orphée Cugat

\section{To cite this version:}

Harijaona Lalao Rakotoarison, Frédéric Wurtz, Jiri Stepanek, Benoît Delinchant, Orphée Cugat. Integration of the volume segmentation method into an optimization process: application to the sizing of a micro-actuator for deformable mirrors. IEEE Transactions on Magnetics, Apr 2006, France. pp.1163-1166. hal-00333819

\section{HAL Id: hal-00333819 https://hal.science/hal-00333819}

Submitted on 24 Oct 2008

HAL is a multi-disciplinary open access archive for the deposit and dissemination of scientific research documents, whether they are published or not. The documents may come from teaching and research institutions in France or abroad, or from public or private research centers.
L'archive ouverte pluridisciplinaire HAL, est destinée au dépôt et à la diffusion de documents scientifiques de niveau recherche, publiés ou non, émanant des établissements d'enseignement et de recherche français ou étrangers, des laboratoires publics ou privés. 


\title{
Integration of the Volume Segmentation Method Into an Optimization Process: Application to the Sizing of a Micro-Actuator for Deformable Mirrors
}

\author{
H. L. Rakotoarison, F. Wurtz, J. Stepanek, B. Delinchant, and O. Cugat \\ Laboratoire d'Electrotechnique de Grenoble, INPG/UJF- CNRS, 38402 Saint Martin d'Hĕres, France
}

\begin{abstract}
This work comes from the demand of the optimization of an elementary micro-actuator of a deformable mirror. First, we have created a generator which package an electromagnetic solver based on the volume segmentation method into a standard software component. An experiment and a finite-element method simulation are done to validate the model of the elementary micro-actuator. Finally, a process of optimization and Pareto methodology are used to choose the efficient coil shape between two suggested structures.
\end{abstract}

Index Terms-Dipolar moment method, magnetic microsystem, micro-actuator, multiobjective optimization.

\section{INTRODUCTION}

$\mathbf{M}$ ICROSYSTEMS designers meet some problems when they want to manufacture prototypes of electromagnetic micro-actuators. This is caused by the cost and the time that they spend, so it is necessary to optimize the shape of the device before its manufacturing.

Electromagnetic microsystems are frequently made of micromagnets and micro-conductors. To optimize effectively such a structure, a modeling using the volume segmentation method such as Dipole3D [1] is efficient.

However, it is not possible to connect Dipole3D directly into our optimization software, because the optimizer needs a model based on a software standard.

So, an automatic model generator is built to satisfy this requirement. It allows the capitalization of our approach to other micro-actuator modeling.

After the model has been generated, a validation on a FEM simulation and on an experiment is presented.

Finally, this paper discusses the optimization process and the methodologies used to compare two suggested structures.

\section{Description of the InTEgRation OF THE MODEL IN A OPTIMIZATION SOFTWARE}

\section{A. Modeling Approach Used}

Dipole3D [1] solves systems made of magnets and conductors by subdividing the system into elementary magnetic dipoles and elementary electric conductors. Then, it computes the interactions of each element by applying the Biot and Savart and magnetic moment theorems. Finally, a summation of all these elementary interactions (fields, forces, or torques) is made.

\section{B. Packaging the Model Into a Standard Software Component}

To ensure the standardization of the models to be optimized, our laboratory strives to establish a software framework in which any form of model (analytical equations, finite-element

Digital Object Identifier 10.1109/TMAG.2006.871623

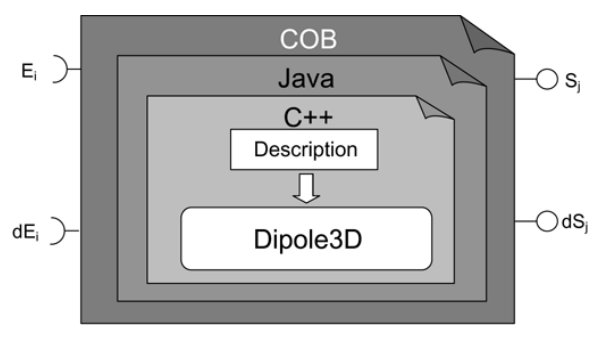

Fig. 1. Component model for sizing.

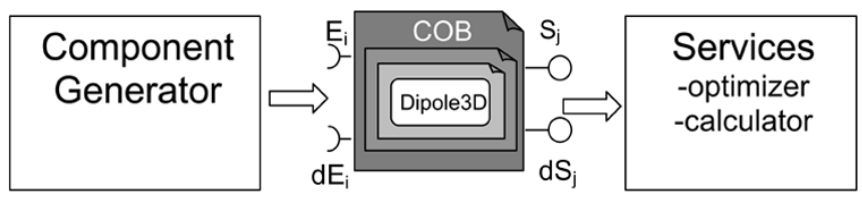

Fig. 2. Component architecture.

model, volume segmentation model, etc.) could be integrated in software components known as computation object (COB) [2]: Physically, it is a file with a ".cob" extension.

This software component has to compute the output parameters of the model as well as the associated sensitivity. So, the COB can be illustrated by a box with inputs (Ei) and outputs $(\mathrm{Sj})$, and their respective differentials $(\mathrm{dEi}, \mathrm{dSj})$.

As shown in Fig. 1, to standardize the model, three software layers are added to the core of Dipole3D.

In our case, the inputs of the COB match the geometric parameters of the device, the currents flowing within the conductors, and the magnetization of the magnets. The outputs represent magnetic fields, forces, or torques.

The architecture around the COB can be divided into two complementary software parts (Fig. 2): on one side several generators, which produce the $\mathrm{COB}$, and, on the other side, services which use the $\mathrm{COB}$, such as optimizers and calculators.

\section{Sensibility Calculation}

The optimizer needs the differentials of the outputs because it exploits a gradient-based algorithm [3]. In our case, the calculation of these differentials is done by finite differences, of which the method is evoked as follows. 
The first step is to compute the partial derivative for each output $S_{j}$ [please see (1), shown at the bottom of the page].

In the data-processing code, this formula is valid for a value of $h_{i}$ which should be selected judiciously: sufficiently small, compared to $E_{\mathrm{i}}$, but not too small, compared to the precision of the computer [4].

The expression of the differential is (2)

$$
\begin{aligned}
d S_{j}=\frac{\partial S_{j}}{\partial E_{1}} \times d E_{1} & +\frac{\partial S_{j}}{\partial E_{2}} \times d E_{2}+\ldots \\
& +\frac{\partial S_{j}}{\partial E_{i}} \times d E_{i}+\ldots+\frac{\partial S_{j}}{\partial E_{n}} \times d E_{n} .
\end{aligned}
$$

\section{Automatic Model Generator}

\section{A. Purpose: Ease of Modeling}

The use of Dipole3D, its integration into a COB, and the computation of the differentials require a solid knowledge in programming languages. However, the microsystems designer may not be a good programmer, so the automatic generator gives an easy way to model their magnetic micro-actuator with a minimum waste of time.

\section{B. No Need to Code Full Programs...Use the Generator}

The designer writes a text file which contains the description of his device, its shape, the magnetization of magnets or the current density of conductors. Descriptions are some simple keywords derived from Dipole3D; its writing is not difficult, but it requires respecting some rules. After defining geometric and physical properties of his device, the user only needs to click on a button of the generator to generate his model.

Fig. 3 shows the internal structure of the generator.

\section{Application to the Modeling of a Micro-Actuator FOR DEFORMABLE MIRROR}

\section{A. Deformable Mirror}

The goal of adaptive optics in astronomy is to compensate in real-time degradations on the images caused by atmospheric turbulence. A deformable mirror (Fig. 4) equipped with electromagnetic micro-actuators [5] is a device used for this purpose.

The objective of our analysis was to find the ideal configuration of the elementary micro-actuator of this mirror, making it possible to develop the maximum of force while consuming a minimum electric power, for a given dimension. Micro-magnets are stuck under the reflective membrane. Fixed micro-coils are placed, respectively, opposite each magnet to control the local deformation of the membrane. Each magnet/coil couple constitutes an elementary electromagnetic micro-actuator.

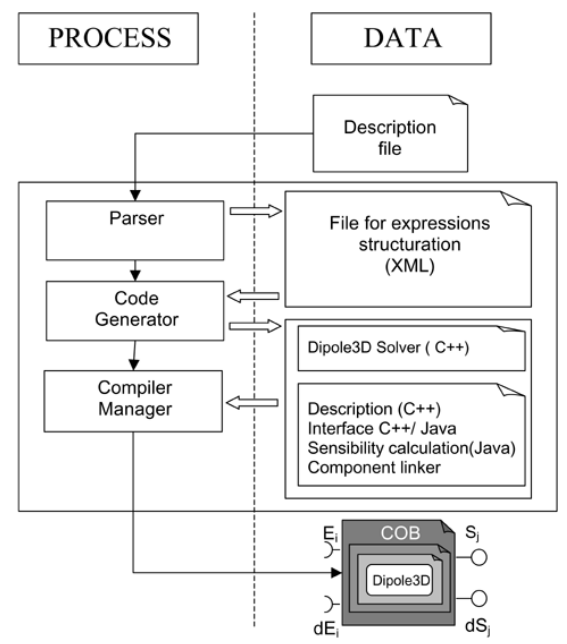

Fig. 3. Internal architecture of the automatic generator.

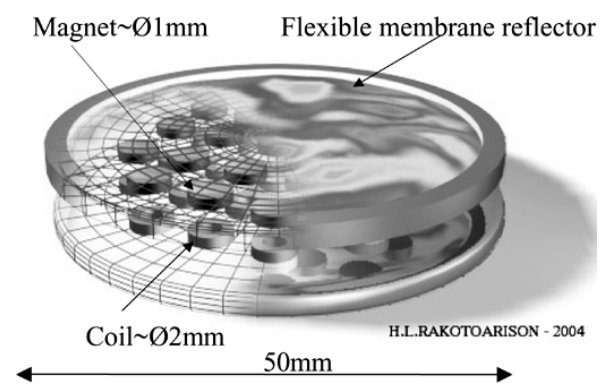

Fig. 4. Electromagnetic deformable mirror.

\section{B. Electromagnetic Micro-Actuator}

Our analysis (modeling and optimization) has helped designers to choose the best structure between two coil shapes, as shown in Fig. 5: (left) the planar structure and (right) the solenoid structure.

\section{Experimental Validation and Finite Element (FLUX2D) Simulation}

The time necessary to optimize the model is related to the object's subdivision (magnet, coil) which constitute the model. According to the desired precision, this time can increase considerably. So, before starting the optimization process, it is significant to validate the model by experimentation on a prototype and/or by simulating a model on FEM software [6] (Fig. 6).

The magnet of the prototype is made of $\mathrm{NdFeB}$ with $1 \mathrm{~T}$ of magnetization, the coil contains 95 turns, and the wire diameter measures $0.1 \mathrm{~mm}$.

Modeling in FLUX2D and Dipole3D also takes into account the fill factor of the coil. Fig. 7 gives a comparison and allows the validation of the model.

$$
\frac{\partial S_{j}}{\partial E_{i}}=\lim _{h_{i} \rightarrow 0} \frac{S_{j}\left(E_{1}, E_{2}, \ldots, E_{i}+h_{i}, \ldots \cdot E_{n}\right)-S\left(E_{1}, E_{2}, \ldots, E_{i}, \ldots E_{n}\right)}{h_{i}}
$$



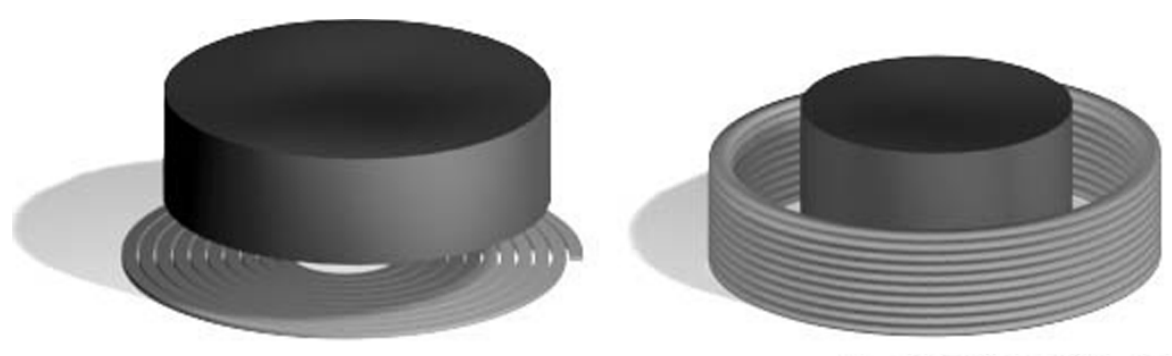

H.L.RAKOTOARISON - 2004

Fig. 5. Two types of elementary micro-actuators.

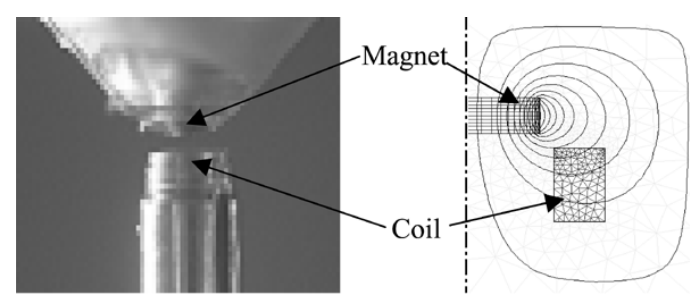

Fig. 6. (Left) Experimentation and (right) FLUX2D simulation.

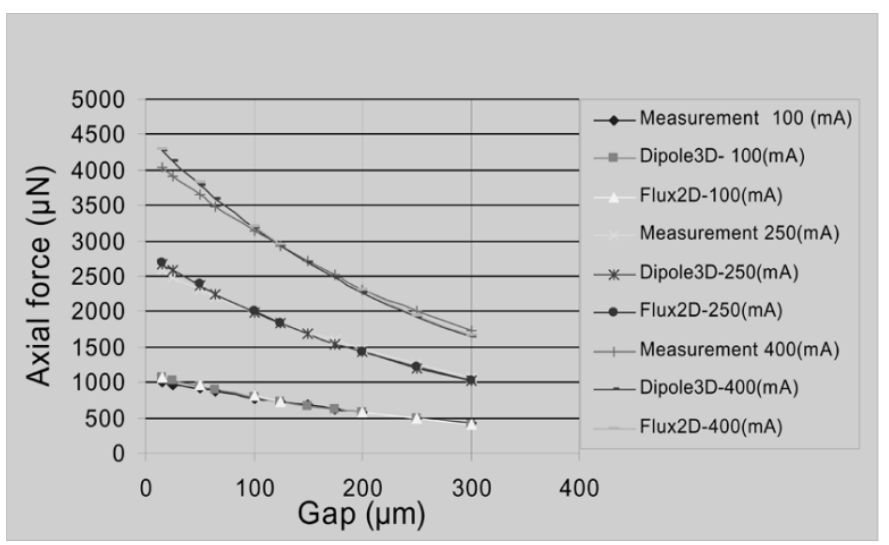

Fig. 7. Comparison between measurements, dipole3D modeling, and FLUX2D simulation.

\section{Model Generation}

Fig. 8 shows the graphic interface of the automatic generator with the commands script used to model the micro-actuator; some comments (text preceding by a " $/ /$ ") are typed in addition to clarify the model.

The first two command lines after the comment are the geometrical and physical description of the magnet.

The next command line adds a spatial translation to the magnet.

The next two command lines define the geometry and the current density of the coil.

The last two command lines indicate that the computation of the force is applied on the magnet.

\section{E. Model Specifications}

The device is intended to correct images. The first significant factor is the resolution: As the surface occupied by each microactuator gets smaller, the resulting image improves.

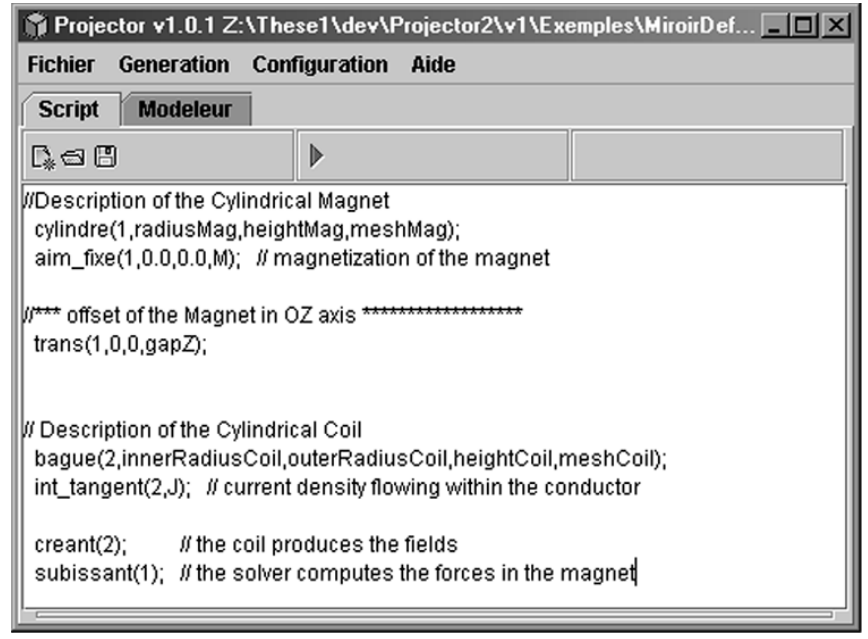

Fig. 8. Modeling command script for the automatic generator.

TABLE I

CONSTRAINTS ON THE INPUT PARAMETERS OF THE MODEL

\begin{tabular}{|c|c|c|c|}
\hline Input parameters & Unit & Planar & Solenoid \\
\hline Magnet height & $\mathrm{mm}$ & {$[0 ; 0.5]$} & {$[0 ; 0.6]$} \\
\hline Magnet magnetisation M & $\mathrm{T}$ & 1 & 1 \\
\hline gapZ & $\mathrm{mm}$ & 0.02 & \pm 0.01 \\
\hline Coil Radius & $\mathrm{mm}$ & {$[0 ; 0.85]$} & {$[0.5 ; 0.85]$} \\
\hline Coil height & $\mathrm{mm}$ & {$[0 ; 0.5]$} & {$[0 ; 1]$} \\
\hline Coil Current density J & $\mathrm{A} / \mathrm{mm}^{2}$ & {$[0 ; 100]$} & {$[0 ; 100]$} \\
\hline
\end{tabular}

TABLE II

CONSTRAints ON THE OUtPUT PARAMETERS OF THE MOdel

\begin{tabular}{|c|c|c|c|}
\hline Output parameters & Unit & Planar & Solenoid \\
\hline Axial force & $\mathrm{mN}$ & 1 & 1 \\
\hline Heat losses & $\mathrm{W}$ & minimum & minimum \\
\hline
\end{tabular}

The constraints on the input parameters (Table I) of the model are shown in Table I.

With the preceding constraints come constraints on the outputs (Table II) of the model: the force developed by each microactuator and the heat losses by the coil, which is also the objective function.

\section{F. Optimization Result}

After having plugged the model into the software optimizer (CDI-Optimizer [7]) and configured its input and output parameters according to specifications, the optimization process was 


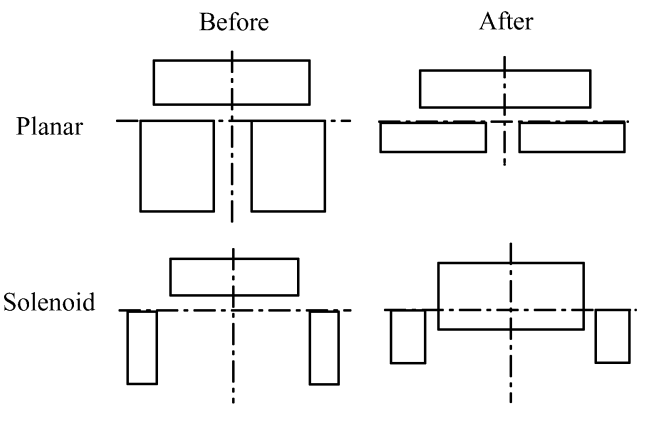

Fig. 9. Geometry evolution before and after optimization.

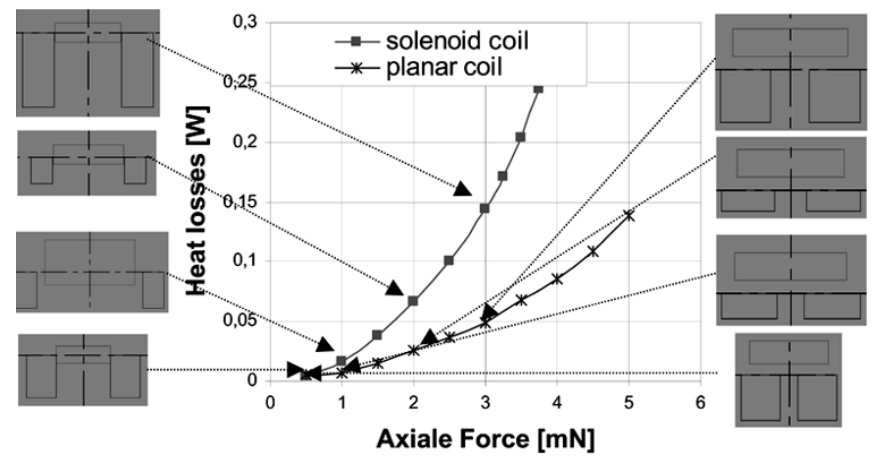

Fig. 10. Comparison showing the effectiveness of the planar coil.

launched; a determinist algorithm based on SQP approach was chosen [8].

Fig. 9 shows the geometrical evolution of the two structures before and after optimizations.

\section{G. Multiobjective Optimization}

With the same specifications on the input parameters, each model was optimized for several output parameters (for several values of a given force, the values of the Joule losses were minimized). Hence, each optimization process gives a new shape to each structure. This method is known as the Pareto boundary [9].
The result demonstrates (Fig. 10) that for any given force, and at a constrained diameter, the associated planar structure is more efficient than the solenoid structure.

\section{CONCLUSION}

The integration of the volume segmentation method (implemented in Dipole3D) into optimization software was done to meet the demand for microsystems modeling. The automatic generator was created in the aim to offer to microsystems designers a handy tool which helps them to size their devices. It was applied to the modeling of the micro-actuator for the deformable mirror. The optimization result gives the best structure between two coils shape.

\section{REFERENCES}

[1] J. Delamare, E. Rulliere, and J. P. Yonnet, "3D Calculation of permanent magnet interaction," in Proc. IMACS TC, 1993, pp. 289-292.

[2] B. Delinchant, F. Wurtz, E. Atienza, and J. Bigeon, "New working possibilities to electrical software thanks to component methodologies," in Proc. 7th Int. Conf. Modeling and Simulation of Electric Machines, Converters and Systems, Montréal, QC, Canada, Aug. 2002, pp. 18-21.

[3] C. Singh and D. Sarker, "Pratical considerations in the optimization of induction motor design," Proc. IEEE, vol. 139, no. 4, pp. 365-373, Apr. 1992.

[4] B. Delinchant, F. Wurtz, and E. Atienza, "Reducing sensivity analysis time cost of compound model," IEEE Trans. Magn., vol. 40, no. 2, pp. 1216-1219, Mar. 2004.

[5] O. Cugat, P. Mounaix, S. Basrour, C. Divoux, and G. Reyne, "Deformable magnetic mirror for adaptive optics: Technological aspects," Sens. Actuators A, pp. 1-9, 2001.

[6] [Online]. Available: http://cedrat.com/

[7] B. Delinchant, F. Wurtz, D. Magot, and L. Gerbaud, "A componentbased framework for the composition of simulation software modeling electrical systems," Soc. Model. Simul., vol. 80, no. 7-8, pp. 347-356, Jul./Aug. 2004.

[8] F. Wurtz, J. Bigeon, and C. Poirson, "A methodology and a tool for the computer aided design with constraints of electrical devices," IEEE Trans. Magn., vol. 32, no. 3, pp. 1429-1432, May 1996.

[9] I. Das and J. E. Denis, "Normal-boundary intersection: A new method for generating the pareto surface in nonlinear multicriteria optimization problems," SIAM J. Optim., vol. 8, no. 3, pp. 213-226, 1986.

Manuscript received June 25, 2005 (e-mail: lalao.rakotoarison-harijaona@leg.ensieg.inpg.fr). 